\title{
PELAKSANAAN DOKUMENTASI ASUHAN KEBIDANAN TERHADAP PERLINDUNGAN HUKUM PASIEN PADA BIDAN PRAKTIK MANDIRI (Studi di Kabupaten Cilacap) Oleh: DEWI PUSPITASARI ${ }^{1}$
}

\begin{abstract}
There are still many Independent Practical Midwives in Cilacap District who have not systematically carried out midwifery documentation even though it is needed to know the progress in patient care. This is because midwives have obligations as stipulated in the Regulation of the Minister of Health No. 28 of 2017 on Article 28, namely that midwives have the obligation to systematically record documentation. Registration of midwifery care must be recorded in accordance with midwifery service standards in accordance with Kepmenkes No. 369 of 2007 concerning Midwife Professional Standards. Therefore, this study examines the implementation of midwifery care documentation on BPM and patient legal protection at BPM in Cilacap Regency.

This research uses sociological juridical approach, with analytic descriptive type, and using primary data through interview and docuent study with Head of Health Service and Community Resource of Cilacap District Health Office, Head of IBI Branch of Cilacap District, each Head of Branch of Cilacap District, Practice of Midwife in Cilacap District.

The results showed that the implementation of documentation on BPM was not in accordance with the Decree of the Ministry of Health 369 of 2007 because there were still midwives using the narrative model recording technique to record everything that was examined by the midwife without mentioning the patient's progress notes. Constraints to the implementation of midwifery care documentation on patient legal protection at BPM in Cilacap Regency are documentation of non-systematic documentation due to lack of awareness of midwives in carrying out systematic documentation, and monev conducted not periodically only when SIPB is extended. So what needs to be considered to solve the problem is that socialization continues to be improved regarding documentation at the $B P M$ according to the midwife's professional standards, periodically monitoring the BPM, and giving strict sanctions to the violating midwife.
\end{abstract}

Key words: independent practice midwives, midwifery care documentation, legal protection

\begin{abstract}
ABSTRAK
Masih banyaknya Bidan Praktik Mandiri di Kabupaten Cilacap yang belum melaksanakan dokumentasi keidanan secara sistematis padahal sangat dibutuhkan untuk mengetahui perkembangan dalam pelayanan pasien. Hal ini disebabkan karena bidan mempunyai kewajiban sebagaimana Permenkes No 28 Tahun 2017 pada Pasal 28 yaitu bidan mempunyai kewajiban melakukan pencatatan dokumentasi secara sistematis. Pencatatan asuhan kebidanan harus dicatat sesuai dengan standar pelayanan kebidanan sesuai dengan Kepmenkes No 369 Tahun 2007 tentang Standar Profesi Bidan. Oleh karena itu penelitian ini mengkaji tentang pelaksanaan dokumentasi asuhan kebidanan pada BPM dan perlindungan hukum pasien pada BPM di Kabupaten Cilacap.

Penelitian ini menggunakan metode pedekatan yuridis sosiologis, dengan tipe deskriptif analitik, dan menggunakan data primer melalui wawancara dan studi dokumentasi.

Hasil penelitian menunjukan bahwa pelaksanaan dokumentasi pada BPM belum sesuai dengan Kepmenkes 369 Tahun 2007 karenan masih terdapat bidan menggunakan teknik pencatatan model naratif yaitu mencatat apa saja yang diperiksa oleh bidan tanpa mencantumkan catatan perkembangan pasien. Kendala pelaksanaan
\end{abstract}

\footnotetext{
${ }^{1}$ dewipuspita2728@gmail.com
} 
dokumentasi asuhan kebidanan terhadap perlindungan hukum pasien pada BPM di Kabupaten Cilacap yaitu pencatatan dokumentasi yang tidak sistematis disebabkan karena kurangnya kesadaran bidan dalam melaksanakan dokumentasi secara sistematis, dan monev yang dilakukan tidak secara berkala hanya dilakukan pada saat perpanjangan SIPB. Sehingga yang perlu dipertimbangkan untuk menyelesaikan permasalahan yaitu sosialisasi terus ditingkatkan mengenai dokumentasi pada BPM sesuai standar profesi bidan, melakukan monev kepada BPM secara berkala, dan pemberian sanksi yang tegas bagi bidan yang melanggar.

Kata kunci: bidan praktik mandiri, dokumentasi asuhan kebidanan, perlindungan hukum

\section{A. PENDAHULUAN}

Bidan sebagai pemberi pelayanan harus menjamin pelayanan yang profesional dan akuntabilitas serta aspek legal dalam pelayanan kebidanan. $^{2}$ Ketika bidan dalam melakukan upaya kesehatan tidak sesuai kewenangannya, maka berisiko terjadi penyimpangan kewenangan. Risiko tersebut dapat berupa pelanggaran terhadap hak pasien. Pelanggaran hak pasien akan berakibat terancamnya keselamatan pasien, dimana tidak adanya perlindungan hukum bagi pasien. Oleh karena itu untuk mencegah agar tidak terjadi pelanggaran tersebut maka bidan praktik mandiri perlu ditingkatkan mutu pelayanannya. Mutu pelayanan kebidanan berorientasi pada penerapan kode etik dan standar pelayanan kebidanan, serta kepuasan yang mengacu pada penerapan semua persyaratan pelayanan kebidanan. Dari dua dimensi mutu pelayanan kebidanan tersebut, tujuan akhirnya adalah

${ }^{2}$ Octa Ristica Dwienda, 2014, Widya Juliarti, Prinsip Etika dan Moralitas Dalam Pelayanan Kebidanan, Yogyakarta: Deepublish, hlm. 27. kepuasan pasien yang dilayani oleh bidan. Pelayanan kebidanan tersebut meliputi pendeteksian keadaan abnormal pada ibu dan anak, melaksanakan konseling dan pendidikan kesehatan terhadap individu, keluarga dan masyarakat. ${ }^{3}$

Pelaksanaan Peraturan Menteri Kesehatan Nomor 28 Tahun 2017 Tentang Izin Dan Penyelenggaraan Praktik Bidan pada Pasal 28 huruf (e) menjelaskan bahwa "Dalam melaksanakan praktek / kerja, bidan berkewajiban untuk melakukan pencatatan asuhan kebidanan dan pelayanan lainnya secara sistematis". Menurut Keputusan Menteri Kesehatan Nomor 369 / MENKES / SK / III / 2007 Tentang Standar Profesi Bidan yang terdapat pada standar pelayanan bidan yaitu standar VII menjelaskan pengelola pelayanan kebidanan memiliki standar asuhan / manajemen kebidanan yang diterapkan sebagai pedoman dalam memberikan pelayanan kepada pasien diantaranya diagnosa kebidanan, rencana asuhan kebidanan, dokumen

\footnotetext{
${ }^{3}$ Moh. Wildan dan A. Aziz Alimul Hidayat, 2008, Dokumentasi Kebidanan, Jakarta: Salemba Medika, hlm. 3.
} 
tertulis tentang tindakan kebidanan dan catatan perkembangan pasien dalam asuhan kebidanan.

Pada kenyataannya bidan belum melakukan dokumentasi kebidanan sesuai standar. Menurut Farid Husin dalam International Conference on Women's Health in Science and Engineering, di Bandung pada tanggal 6 Desember 2012 halaman 28 dijelaskan hasil penelitian pada berbagai RS / RSUD, PUSKESMAS, BPM di Jawa Barat adalah asuhan kebidanan diberikan berbeda-beda antara fasilitas pelayanan kesehatan dan seringkali tidak komprehensif atau kurang paripurna, kerangka kerja sering tidak berdasarkan Subjektif, Objektif, Analisa, dan Penatalaksanaan (SOAP), asuhan kebidanan tidak sesuai dengan standar, dan pendokumentasian tidak lengkap dan tidak sistematis. ${ }^{4}$

Menurut bidan yang bekerja di Bidan Praktik Mandiri Kabupaten Cilacap pelaksanaan dokumentasi kebidanan dilakukan tidak secara sistematis seperti teori. Pertama pasien datang ditanyakan data diri pasien, keluhan pasien, kemudian hasil pemeriksaan fisik dicatat oleh bidan tetapi rencana asuhan tidak dicantumkan. ${ }^{5}$ Memperhatikan data awal

${ }^{4}$ Farid husin, 2012, International Conference on Women's Health in Science and Engineering, tersedia di website http://wisehealth.itb.ac.id/files/kebidanan/IT B DES2012, EDIT.pdf, diakses 30 Januari 2017

${ }^{5}$ Wawancara dengan bidan pada tanggal 12 Agustus 2017 seperti masih kurangnya dokumentasi asuhan kebidanan yang belum sesuai dengan standar profesi bidan dan standar asuhan kebidanan, maka mendorong peneliti untuk melakukan penelitian dengan mengambil judul "Pelaksanaan Dokumentasi Asuhan Kebidanan Terhadap Perlindungan Hukum Pasien Di Bidan Praktik Mandiri"

\section{B. PERUMUSAN MASALAH}

Berdasarkan latar belakang tersebut diatas maka dapat diambil suatu rumusan masalah sebagai berikut:

1. Apakah pelaksanaan dokumentasi asuhan kebidanan pada Bidan Praktik Mandiri Kabupaten Cilacap sudah sesuai dengan standar asuhan kebidanan sebagaimana diatur dalam Keputusan Menteri Kesehatan Nomor 369 / MENKES / SK / III / 2007 ?

2. Apakah yang menjadi kendala dalam pelaksanaan dokumentasi asuhan kebidanan terhadap perlindungan hukum pasien pada Bidan Praktik Mandiri di Kabupaten Cilacap ?

\section{METODE PENELITIAN}

Pendekatan dalam penelitian ini adalah yuridis sosiologis dengan tipe penelitian adalah deskriptif 
analitis. Lokasi dari penelitian ini adalah Bidan Praktik Mandiri (BPM) di Kabupaten Cilacap. Untuk sumber data, diperoleh dari data primer dengan metode wawancara data sekunder dengan melakukan studi dokumen. Kemudian data di analisis metode kualitatif dan disajikan dalam bentuk teks naratif. Metode pengambilan sampel menggunakan purposive sampling.

\section{PEMBAHASAN}

\section{Pelaksanaan}

Dokumentasi

Asuhan Kebidanan sesuai dengan Standar Asuhan

Kebidanan Sebagaimana diatur dalam Kepmenkes No 369/Menkes/SK/III/2007 pada

Bidan Praktik Mandiri Kabupaten Cilacap

$$
\text { Wawancara dengan } 6
$$

Bidan Praktek Mandiri (BPM) masing masing ranting di Kabupaten Cilacap dalam melaksanakan manajemen kebidanan yaitu dokumentasi asuhan kebidanan dengan hasil sebagai berikut: ${ }^{6}$

a. Responden 1 Ranting Kotatip Puskesmas Cilacap Utara 2

$\begin{array}{rr}\text { Bidan } & \text { Praktik } \\ \text { Mandiri } & \text { dalam }\end{array}$

${ }^{6}$ Wawancara dengan Bidan Praktik Mandiri (BPM) pada tanggal 20 Desember 2017. melaksanakan dokumentasi asuhan kebidanan tidak menggunakan SOAP seperti yang dilaksanakan di Rumah Sakit. Di bidan hanya menggunakan catatan dalam bentuk naratif meliputi hasil pemeriksaaan fisik pasien dan untuk catatan perkembangan pasien tidak dicantumkan dalam dokumentasi tetapi dilaksanakan oleh bidan seperti untuk pasien yang akan bersalin sebelum pembukaan lengkap harus makan dan minum agar memiliki tenaga dan tidak lemas.

Dilakukan

monitoring dan evaluasi hanya pada saat perpanjangan Surat ljin Praktik Bidan. Tidak ada monitoring dan evaluasi secara rutin.

b. Responden 2 Ranting Kotatip Rumah Sakit Manajemen

kebidanan yang dibuat belum mengunakan SOAP yang dilengkapi dengan catatan perkembangan pasien. Bidan masih menunggu buku habis karena format dalam satu buku harus sama tidak bisa 
dicampur dengan format lain. Bidan juga belum bisa pindah buku yang baru apabila satu buku belum habis hingga halaman terakhir.

\section{Dilakukan}

monitoring dan evaluasi hanya pada saat perpanjangan Surat ljin Praktik Bidan. Selain itu tidak ada monitoring dan evaluasi lagi dari Dinas Kesehatan.

c. Responden 3 Ranting Kroya Dokumentasi yang digunakan di Bidan Praktek Mandiri menggunakan sistem dokumentasi Subjectif, Objectif, Assessment, Planning (SOAP) dengan melampirkan catatan perkembangan. Keuntungan menggunakan dokumentasi asuhan kebidanan SOAP dapat memberikan asuhan kebidanan yang berkesinambungan.

Dilakukan monitoring dan evaluasi hanya pada saat perpanjangan Surat ljin Praktik Bidan. Selain itu hanya evaluasi yang dilakukan hanya antar bidan saja. Sebagai bahan koreksi unntuk lebih meningkatkan

pencatatan dokumentasi yang sistematis sesuai dengan evidence based yaitu pelayanan yang bermutu sesuai dengan asuhan kebidanan sehingga dapat sesuai dengan standar profesi bidan.

d. Responden 4 Ranting Cilacap

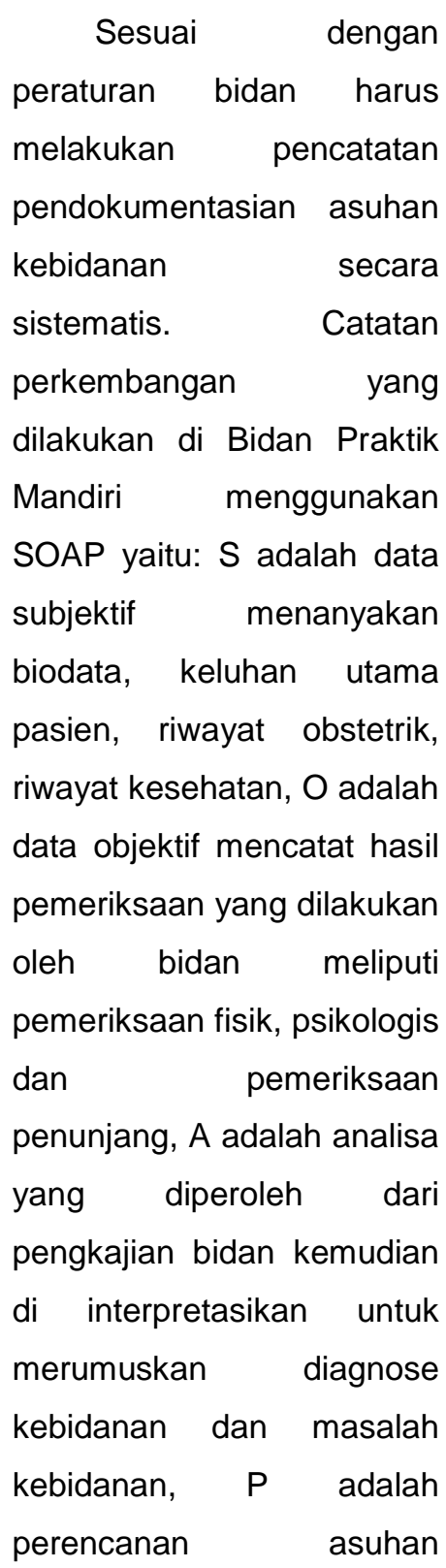


kebidanan yang akan
dilakukan bidan berdasakan
diagnosa dan masalah
kebidanan yang terjadi pada
pasien.

Dilakukan monitoring dan evaluasi hanya pada saat perpanjangan Surat ljin Praktik Bidan. Ikatan Bidan juga melaksanakan evaluasi hasil pendokumentasian asuhan kebidanan untuk memastikan bahwa dokumentasi ynag dilakukan sudah sesuai dengan standard an asuhan yang diberikan bermanfaat untuk pasien.

e. Responden 5 Ranting Majenang Bidan sudah mengetahui pendokumentasian asuhan kebidanan harus secara sistematis karena sangat berguna bagi pasien dan bidan. Bagi pasien lama maupun pasien baru berguna karena memiliki catatan agar bidan dalam melakukan pelayanan asuhan kebidanan sesuai dengan standar profesi bidan. Dilakukan monitoring dan evaluasi hanya pada saat perpanjangan Surat ljin Praktik Bidan.

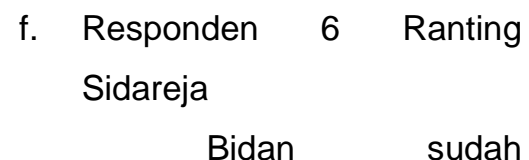
mengetahui dokumentasi asuhan kebidanan sesuai dengan Peraturan Menteri Kesehatan tentang ijin dan penyelenggaraan praktik bidan yaitu dokumentasi harus dilakukan secara sistematis dan sesuai dengan standar profesi bidan agar semua tindakan asuhan yang dilakukan oleh bidan sesuai dengan kondisi pasien. Dilakukan monitoring dan evaluasi hanya pada saat perpanjangan Surat Ijin Praktik Bidan.

Berdasarkan hasil wawancara dari narasumber diperoleh data sebagai berikut:

a. Wawancara dengan Kepala Dinas Kesehatan Kabupaten Cilacap:

Bahwa bidan menjalankan tugasnya berpedoman pada Peraturan Menteri Kesehatan Nomor 28 Tahun 2017 Tentang Izin dan Penyelenggaraan Praktik Bidan. Dinas Kesehatan Kabupaten Cilacap belum mengetahui jika ada Bidan Praktik Mandiri (BPM) yang 


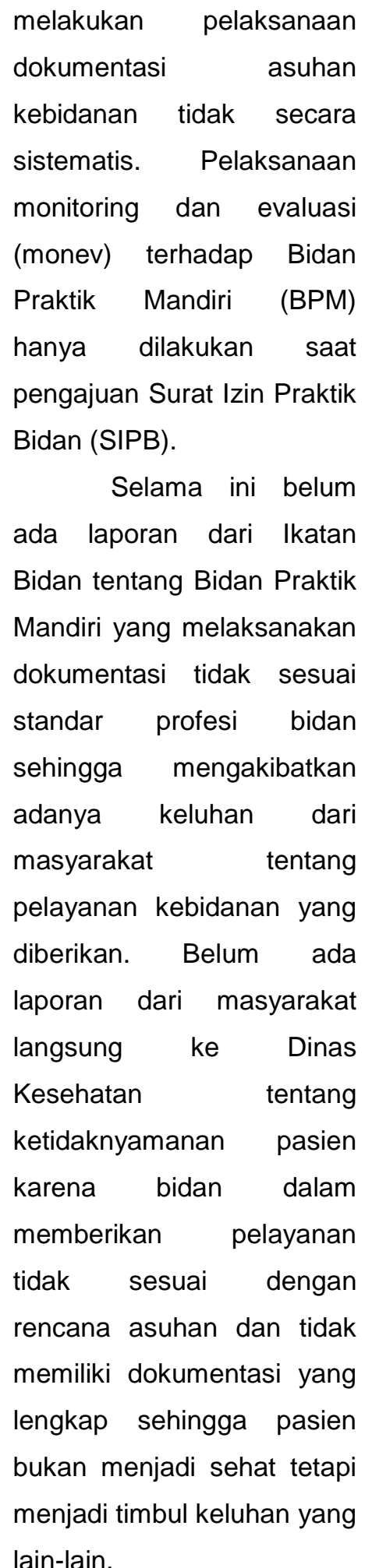

lain-lain.

Dalam rangka

pembinaan

dan

pengawasan

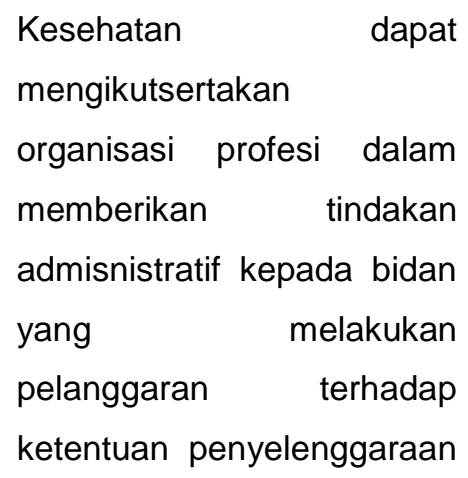

praktik. Namun pada

kenyataannya, tindakan

administratif ini sulit

direalisasikan karena

tekadang pernyataan bidan

fakta dilapangan tidak bisa

dilaksanakan sesuai teori

yang ada. ${ }^{7}$

Menurut penulis,

monev yang dilaksanakan

tidak secara rutin membuat

bidan melaksanakan

dokumentasi kebidanan

tidak secara sistematis.

Dalam hal ini bidan praktik mandiri juga tidak bisa

disalahkan sepenuhnya

dengan membuat

dokumentasi tidak sesuai

standar profesi bidan karena

berjalannya peraturan yang

berlaku harus ada

hubungan antara pihak -

pihak terkait dengan pelayanan kebidanan agar pelayanan kesehatan yang

${ }^{7}$ Wawancara dengan Kepala Dinas Kesehatan Kabupaten Cilacap pada tanggal 08 Desember 2017 
diberikan bidan berjalan dengan efektif.

b. Wawancara dengan Kepala Bidang Pelayanan Kesehatan dan Sumber Daya Masyarakat Dinas Kesehatan Kabupaten

Cilacap : Sistem monitoring dan evaluasi (monev) terhadap Bidan Praktik Mandiri (BPM) hanya dilakukan saat pengajuan Surat Izin Praktik Bidan (SIPB). Pelaksanaan dokumentasi kebidanan yang dilakukan oleh Bidan Praktik Mandiri (BPM) pada tindakan asuhan kebidanan harus sesuai dengan peraturan penyelenggaraan praktik bidan dan standar profesi bidan menurut Keputusan Menteri Kesehatan No 369/ Menkes/SK/III/2007 Tentang Standar Profesi Bidan. Tata cara pengenaan tindakan hukum administrasi adalah saat diketahui adanya pelanggaran yang dilakukan oleh BPM pada saat inspeksi mendadak (sidak) atau adanya laporan dari masyarakat, Dinas Kesehatan Cilacap memberikan teguran lisan terhadap BPM tersebut dengan maksimal teguran lisan maksimal 3 kali dan masa pengawasan selama 1 bulan. Jika BPM masih tetap melakukan pelanggaran, maka akan diberikan teguran tertulis maksimal 3 kali dan pengawasan selama 1 bulan. Setelah diberikan teguran lisan dan tertulis namun BPM masih tetap melakukan pelanggaran, maka Dinas Kesehatan Kabupaten Cilacap akan memberikan tindakan administrasi berupa pecabutan izin sementara bahkan pencabutan izin selamanya. Tata cara pengenaan ini juga disesuaikan dengan efek dari pelanggaran tersebut. Jika pelanggaran tersebut berdampak buruk, misalnya menimbulkan kerugian bagi pasien, maka Bidan Praktik Mandiri dapat langsung diberikan tindakan administrasi berupa pencabutan izin sementara bahkan selamanya. Namun sampai saat ini, belum pernah ada Bidan Praktik Mandiri yang dikenai 


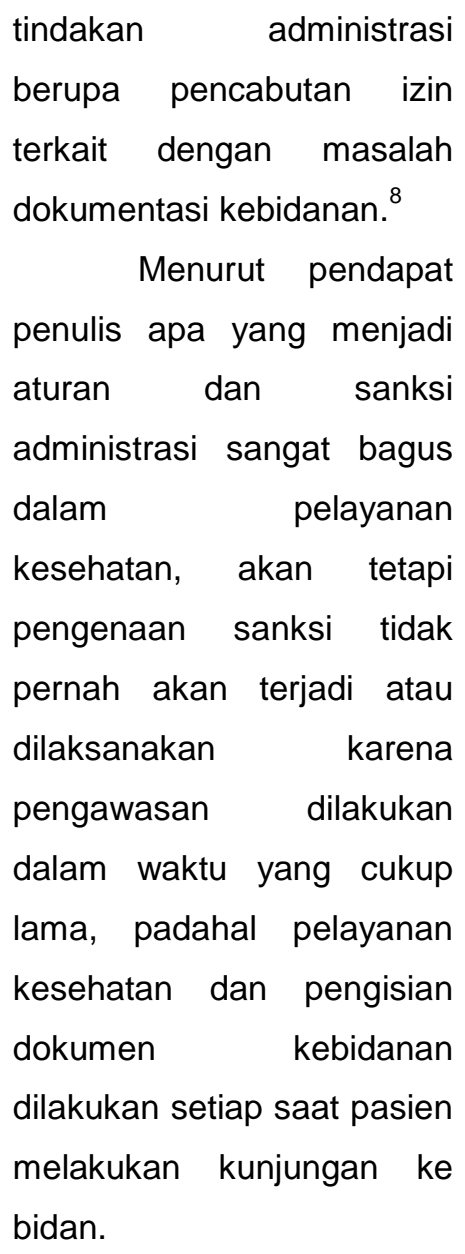

c. Wawancara dengan Ketua Ikatan Bidan Indonesia (IBI) Cabang Kabupaten Cilacap dengan hasil sebagai berikut $:^{9}$ Ikatan Bidan Indonesia (IBI) Cabang Kabupaten Cilacap mengetahui bahwa Bidan Praktik Mandiri (BPM) di Kabupaten Cilacap dalam

\footnotetext{
${ }^{8}$ Wawancara dengan Kepala Bidang Pelayanan Kesehatan dan Sumber Daya Masyarakat Dinas Kesehatan Kabupaten Cilacap pada tanggal 18 Deember 2017.

9 Wawancara dengan Ketua Ikatan Bidan Indonesia (IBI) Cabang Kabupaten Cilacap pada tanggal 18 Desember 2017.
}

melaksanakan manajemen kebidanan khususnya untuk dokumentasi asuhan kebidanan masih ada yang belum sistematis dan belum sesuai dengan standar asuhan kebidanan. Langkah yang diberikan oleh Ketua Ikatan Bidan di Kabupaten Cilacap dengan memberikan informasi dan edukasi mengenai dokumentasi asuhan kebidanan yang seharusnya sesuai dengan Keputusan Menteri Kesehatan Nomor 369/MENKES/SK/III/2007.

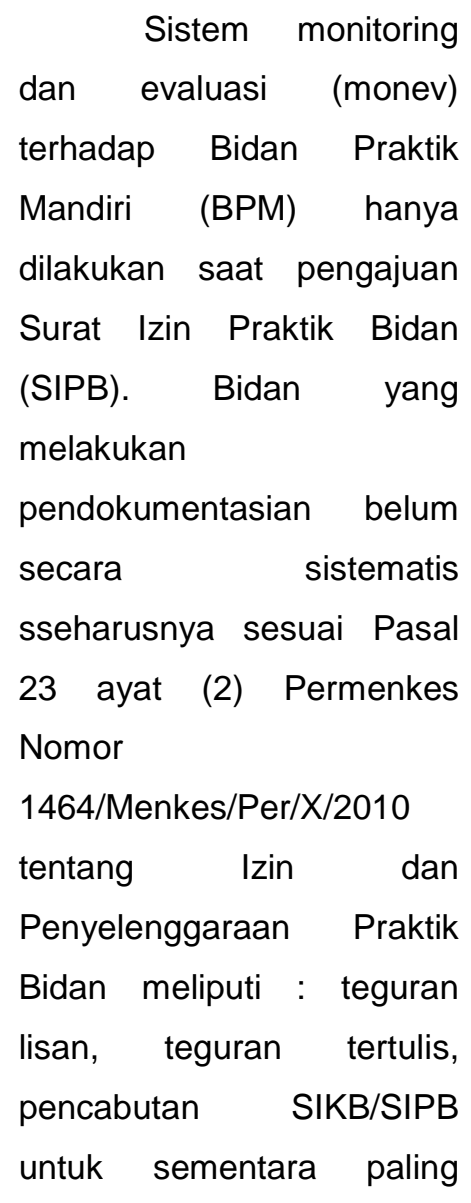


lama 1 (satu) tahun, atau pencabutan SIKB/SIPB selamanya. Namun pada kenyataannya, hal ini tidak dapat dilaksanakan karena yang jadi pedoman bidan adalah memberikan asuhan kebidanan yang sesuai dengan kebutuhan kondisi pasien dan untuk pelaksanaan dokumentasi dapat dilakukan setelah melakukan tindakan asuhan kebidanan.

\section{Kendala Dalam Pelaksanaan} Dokumentasi

Asuhan

Kebidanan Terhadap

Perlindungan Hukum Pasien pada Bidan Praktik Mandiri

Pencatatan asuhan
kebidanan dilakukan segera
setelah melaksanakan asuhan
pada formulir yang tersedia
(Rekam medis/ KMS (Kartu
Menuju Sehat)/Status
pasien/Buku KIA (Kesehatan
lbu dan Anak). Ditulis dalam
bentuk catatan perkembangan
SOAP yaitu S adalah data
subjektif, mencatat hasil
anamnesa, O adalah data
objektif, mencatat hasil
pemeriksaan, A adalah hasil
analisa, mencatat diagnosa
dan masalah kebidanan, P
adalah penatalaksanaan,

mencatat seluruh perencanaan dan penatalaksanaan yang sudah dilakukan seperti tindakan antisipatif, tindakan segera, tindakan secara komprehensif ; penyuluhan, dukungan, kolaborasi, evaluasi/ follow up dan rujukan.

\section{Sementara}

berdasarkan wawancara yang dilakukan terhadap Bidan Praktik Mandiri (BPM) yang belum melaksanakan dokumentasi asuhan kebidanan secara sistematis di Kabupaten Cilacap, maka diperoleh faktor-faktor penyebab bidan yang belum melakukan dokumentasi asuhan kebidanan secara sistematis di BPM, yaitu $:^{10}$

a. Sudah terbiasa melaksanakan dokumentasi asuhan kebidanan dengan cara bidan tersebut dan tentunya masing-masing bidan memiliki cara yang berbeda dalam melaksanakan dokumentasi asuhan kebidanan di Bidan Praktik Mandiri. Sejauh ini bidan tidak mendapatkan masalah tentang dokumentasi asuhan

10 Wawancara dengan di Bidan Praktik Mandiri (BPM) pada tanggal 15 Desember 2017. 


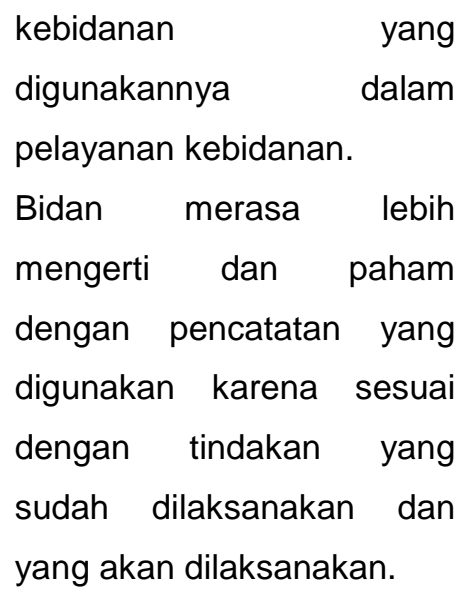

c. Adanya anggapan bahwa dokumentasi asuhan kebidanan itu adalah hanya catatan perkembangan pasien yang yang harus dilaksanakan oleh bidan, jadi apapun model pencatatan dokumentasi kebidanan yang dilaksanakan tidak memiliki dampak yang merugikan bagi bidan maupun pasien. Sehingga dokumentasi tersebut terkadang tidak lengkap dan akurat.

d. Adanya anggapan dokumentasi secara teori susah untuk diterapkan dalam praktek yang nyata karena situasi kondisi di setiap Bidan Praktik Mandiri tidak sama. Adanya keterbatasan tenaga bidan yang bekerja disetiap Bidan Praktik Mandiri (BPM) membuat dokumentasi dilakukan kadang-kadang tidak sistematis tetapi dianggap bidan dokumentasi tersebut sudah lengkap.

e. Bidan beranggapan dokumentasi dengan model SOAP yang sistematis hanya diterapkan jika di rumah sakit jika di Bidan Praktik Mandiri dokumentasi yang dilakukan hanya catatan data diri pasien, dan hasil pemeriksaan bidan. Bidan tidak melakukan rencana asuhan kebidanan.

Faktor yang menjadi kendala dalam pelaksanaan dokumentasi terhadap perlindungan hukum pasien pada Bidan Praktik Mandiri di Kabupaten Cilacap antara lain :

1. Faktor Hukum/UndangUndang

Dalam penelitian ini, Undang-Undang yang dimaksud adalah Undang Undang Nomor 36 Tahun 2009 tentang Kesehatan, Undang - Undang Nomor 29 Tahun 2014 Tentang Praktik Kedokteran, Peraturan Menteri Kesehatan Nomor 28 Tahun 2017 Tentang Izin dan Penyelenggaraan Praktik Bidan, Keputusan Menteri Kesehatan No. 369 / 


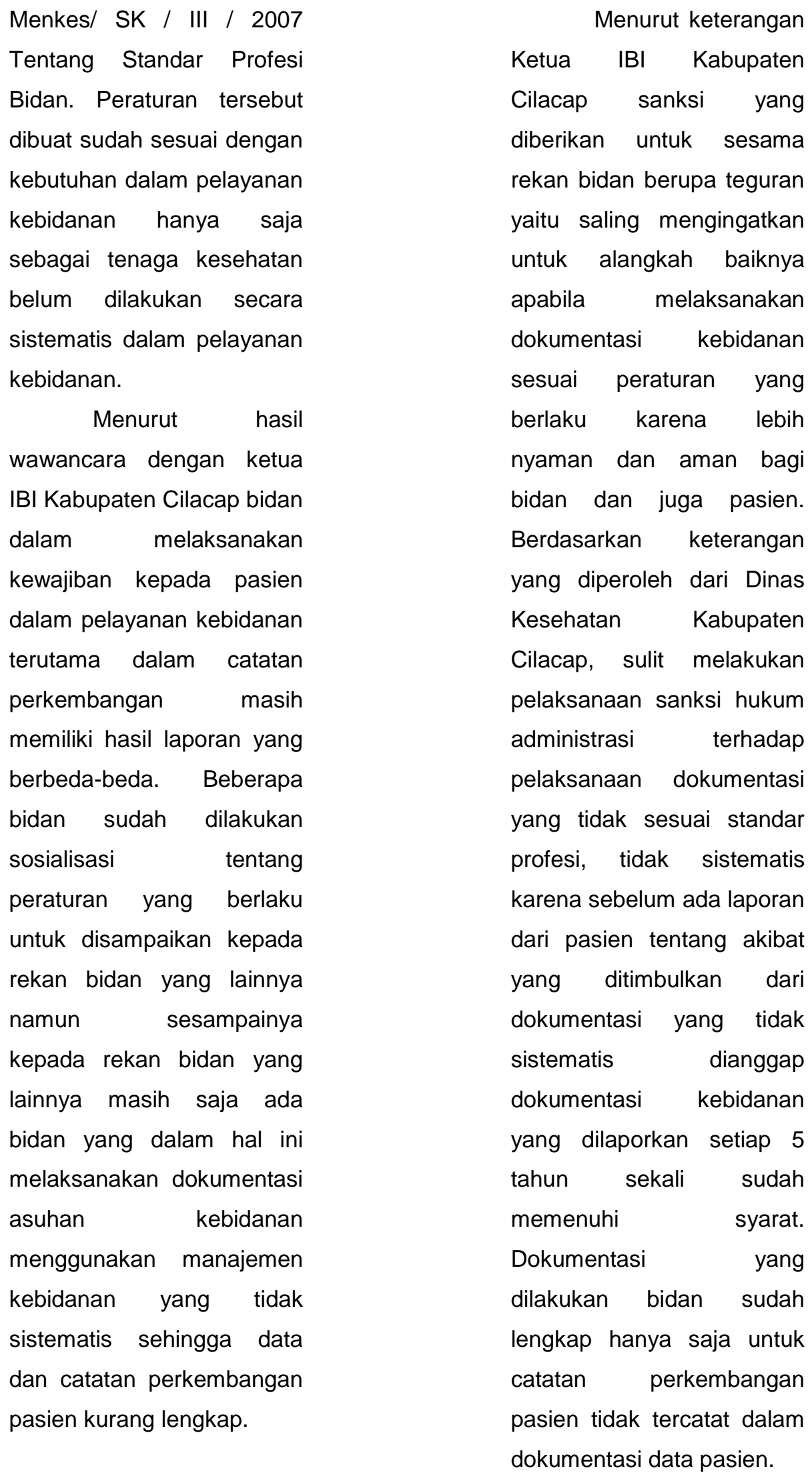


2. Faktor Penegak Hukum

Penegak hukum

dalam penelitian ini adalah

Dinas

Kesehatan

Kabupaten Cilacap. Kepala

Bidang

Pelayanan

Kesehatan dan Sumber

Daya

Masyarakat

Kesehatan Dinas Kesehatan

Kabupaten Cilacap dengan

menyatakan bahwa sistem

monitoring dan evaluasi

(monev) terhadap Bidan

Praktik Mandiri (BPM)

hanya dilakukan saat

pengajuan Surat Izin Praktik

Bidan (SIPB) dan tidak

dilakukan monev secara

berkala. $^{11}$

Dari hasil penelitian

didapatkan bahwa belum

dilaksanakan penegakan

hukum oleh pihak terkait

yaitu Dinas Kesehatan

Kabupaten Cilacap yang

terlihat dari belum adanya

fungsi pengawasan seperti

yang tercantum dalam Pasal

$182 \quad$ Undang-Undang

Kesehatan Nomor 36 Tahun

2009. Jika dalam

pengawasan ditemukan

adanya pelanggaran oleh

${ }^{11}$ Wawancara dengan Kepala Bidang Pelayanan Kesehatan dan Sumber Daya

Masyarakat Kesehatan Dinas Kesehatan

Kabupaten Cilacap pada tanggal 08

Desember 2017 bidan, maka bidan tersebut

dapat dikenakan sanksi

administrasi yang terdiri dari

teguran lisan, tertulis

sampai dengan pencabutan

SIPB.

3. Faktor Sarana atau Fasilitas

Fasilitas merupakan sarana yang mendukung untuk melaksanakan tindakan atau kegiatan. Tanpa adanya fasilitas tertentu, maka tidak mungkin penegakan hukum akan berlangsung dengan lancar. Sarana atau fasilitas tersebut antara lain mencakup tenaga manusia yang berpendidikan dan terampil, organisasi yang baik, peralatan yang memadai, keuangan yang cukup dan lainnya.

Berdasarkan

wawancara yang dilakukan pada Dinas Kesehatan Kabupaten Cilacap, pengawasan (monev) tidak dilakukan karena belum tersedianya petugas yang mencukupi dan tidak adanya anggaran khusus untuk melakukan pengawasan tersebut. Selain itu, tidak adanya laporan dari pasien yang merasa dirugikan akibat 
dokumentasi yang tidak
sistematis sehingga
tindakan asuhan kebidanan
yang diberikan oleh bidan
tidak sesuai dengan kondisi
pasien menjadi alasan tidak
dilaksanakannya sanksi
administrasi.

Sarana dan fasilitas juga akan mendukung bidan dalam melaksanakan tindakan pelayanan kebidanan yang baik serta pencatatan yang lengkap dan konsisten. Menurut Kementrian Kesehatan (2010) mengatakan bidan dalam menjalankan praktik harus memenuhi persyaratan sesuai dengan peraturan pemerintah dan juga memiliki kelengkapan administrasi.

4. Faktor Masyarakat Penegakan hukum berasal dari masyarakat dan bertujuan untuk mencapai kedamaian di dalam masyarakat. Oleh karena itu dipandang dari sudut tertentu, maka masyarakat dapat mempengaruhi penegakan hukum tersebut.

Dinas Kesehatan, organisasi profesi Ikatan Bidan Indonesia (IBI) dan BPM di Kabupaten Cilacap yang memberikan

pelayanan kebidanan dengan melaksanakan dokumentasi asuhan kebidanan secara sistematis belum pernah mendapat aduan dari pasien yang merasa dirugikan dari pelayanan yang diberikan oleh bidan. Sebagian besar pasien juga tidak mengetahui hak dan kewajiban mereka sehingga dapat menghambat upaya penegakan hukum, antara lain :

a. Tidak mengetahui atau tidak menyadari apabila hak-hak mereka dilanggar atau terganggu

b. Tidak mengetahui akan adanya upaya-upaya hukum untuk melindungi kepentingankepentingannya

c. Tidak mengetahui harus memberikan aduan kemana jika pasien merasa dirugikan.

d. Tidak berdaya untuk memanfaatkan upayaupaya hukum karena faktor-faktor keuangan, 
psikis, sosial, atau

politik

e. Tidak mempunyai pengalaman menjadi anggota organisasi yang memperjuangkan kepentingan-

kepentingan

Bagian terpenting dari masyarakat yang menetukan penegakan hukum adalah kesadaran hukum masyarakat. Semakin tinggi tingkat kesadaran hukum masyarakat, maka akan semakin memungkinkan penegakan hukum yang baik. Kesadaran hukum dalam masyarakat meliputi adanya pengetahuan tentang hukum, penghayatan fungsi hukum, dan ketaatan terhadap hukum.

Dalam kasus ini, masyarakat belum memiliki kesadaran hukum karena belum mengetahui tentang peraturan mengenai bidan dan kewenangannya. Sehingga tidak dapat menghayati fungsi hukum dan mentaati hukum (peraturan) yang berlaku.

5. Faktor Kebudayaan
Kebudayaan pada dasarnya mencakup nilainilai yang mendasari hukum yang berlaku, nilai-nilai yang merupakan konsepsi abstrak mengenai apa yang dianggap baik sehingga dianut dan apa yang dianggap buruk sehingga dihindari. Nila-nilai tersebut lazimnya merupakan pasangan nilai-nilai yang mencerminkan dua keadaan ekstrim yang diserasikan. Pelayanan kesehatan (health care services) merupakan salah satu upaya yang dapat dilakukan untuk meningkatkan derajat kesehatan, baik perseorangan, maupun kelompok atau masyarakat secara keseluruhan. ${ }^{12}$

E. SIMPULAN

Berdasarkan pada hasil penelitian dan pembahasan, maka dapat diambil kesimpulan sebagai berikut :

1. Pelaksanaan dokumentasi kebidanan pada bidan praktik mandiri di Kabupaten Cilacap belum sesuai yang diatur Kepmenkes No. 369 Tahun

\footnotetext{
${ }^{12}$ Veronica Komalawati, 1989,
} Hukum dan Etika Praktik Dokter, Jakarta: Pustaka Harapan, hlm. 30. 
2007 tentang Standar Profesi

Bidan karena masih terdapat

bidan yang menggunakan

teknik pencatatan model naratif

yaitu mencatat apa saja yang

diperiksa oleh bidan tanpa

mencantumkan catatan

perkembangan pasien.

2. Kendala dalam pelaksanaan dokumentasi asuhan kebidanan terhadap pelindungan hukum pasien pada Bidan Praktik Mandiri di Kabupaten Cilacap yaitu:

a. Pencatatan dokumentasi yang tidak sistematis disebabkan karena kurangnya kesadaran bidan dalam melaksanakan dokumentasi secara sistematis.

b. Monev yang dilakukan tidak secara berkala hanya dilakukan pada saat perpanjangan SIPB.

F. SARAN

$$
\begin{aligned}
& \text { Saran-saran yang perlu } \\
& \text { dipertimbangkan } \\
& \text { menyelesaikan permasalahan yang } \\
& \text { ada berdasarkan hasil penelitian } \\
& \text { dan pembahasan yaitu: }
\end{aligned}
$$

a. Sosialisasi terus ditingkatkan mengenai dokumentasi kebidanan pada Bidan Praktik Mandiri sesuai dengan standar profesi bidan dan pemberian contoh format dokumentasi bidan yang memiliki BPM secara keseluruhan.

b. Melakukan monitoring dan evaluasi kepada Bidan Praktik Mandiri secara berkala.

c. Pemberian sanksi yang tegas bagi bidan yang melanggar.

\section{DAFTAR PUSTAKA}

Dwienda, Octa Ristica, Juliarti, Widya, 2014, Prinsip Etika dan Moralitas Dalam Pelayanan Kebidanan. Yogyakarta : Deepublish.

Fajar ND, Mukti, Dkk, 2010, Dualisme Penelitian Hukum Normatif Dan Empiris, Yogyakarta : Pustaka Pelajar.

Hanintjito, Ronny, 1998, Metodologi Penelitian Hukum, Jakarta : Ghalia Indonesia.

Heryani, Reni, 2016, Etikolegal Dalam Praktik Kebidanan, Jakarta : Trans Info Media.

HR, Ridwan, 2014, Hukum Administrasi Negara, Jakarta : Rajawali Pers. , 2014, Etika dan Hukum Kesehatan, Nuha Medika , Yogyakarta.

Kelsen, Hans, 2006, Teori Umum Tentang Hukum Dan Negara Cetakan I,

Bandung : Nusamedia.

Kusnardi, Moh. dan Ibrahim, Harmaily, 1988, Hukum Tata Negara Indonesia, Jakarta : Sinar Bakti.

Komalawati, Veronica, 1989, Hukum dan Etika Praktik Dokter, Jakarta : Pustaka Harapan

Masri dan Effendi, Sofian, 1995, Metode Penelitian Survai, Jakarta: LP3E

Mertokusumo, Sudikno, 2007, Mengenal Hukum Suatu Pengantar, Yogyakarta: Liberty.

Moleong, Lexy j., 2004, Metodologi Penelitian Kualitatif, Bandung Remaja: Rosdakarya. 
Muchtar, Masrudi, 20016, Etika Profesi Dan Hukum Kesehatan, Yogyakarta: Pustaka Baru Press.

Muhamad, Abdulkadir, 2004, Hukum dan Penelitian Hukum. Bandung: PT. Citra Adityabakti.

Nugraha, Safri, dkk. 2007, Hukum Administrasi Negara : Edisi Revisi, Jakarta: Fakultas Hukum Universitas Indonesia.

Nurhayati, Apriani, dan Bustani, Anita , 2012, Konsep Kebidanan, Jakarta : Salemba Medika.

Nurobikha., Farelya, Gita., 2015, Etikolegal Dalam Pelayanan Kebidanan,

Yogyakarta : Deepublish.

Rahardjo S, 1977, Pemanfaatan IImuIImu Sosial Bagi Pengembangan IImu Hukum, Bandung: Alumni.

Rangkuti, Siti Sundari, 2000 Hukum Lingkungan dan Kebijaksanaan Lingkungan Nasional, Surabaya : Airlangga University Press.

Ridwan, Juniarso dan Sudrajat, Achmad Sodik, 2010, Hukum Administrasi Negara dan Kebijakan Pelayanan Publik, ,Bandung : Nuansa.

Rita Y \& Tri Johan Agus Y., 2014, Asuhan Kebidanan Komunitas, Jakarta: Salemba Medika.

Sadi Is, Muhamad, 2015, Etika Hukum Kesehatan, Jakarta: Kencana.

Suherman, 2004, Pengantar Perbandingan Sistem Hukum, Jakarta: Raja Grafindo Persada.

Sulistyaningsih, 2011, Metodologi Penelitian Kebidanan KuantitatifKualitatif, Yogyakarta : Graha IImu.

Sumali, 2003, Reduksi Kekuasaan Eksekutif Di Bidang Peraturan Pengganti Undang-Undang, Malang : UMM

Sidharta, Bernard Arief, 1999, Refleksi Tentang Striktur Hukum: Sebuah Penelitian Tentang Fungsi Kefilsafatan Dan Sifat Keilmuan IImu Hukum Sebagai Landasan Pembangunan IImu Hukum Nasional Indonesia, Bandung: Bandar Maju. , 1996, Butir-Butir Gagasan tentang Penyelenggaraan Hukum dan Pemerintahan yang Layak. Citra Aditya Bakti. Bandung.

Singarimbun, Moh. Kusnardi dan Ibrahim, Harmaily, 1988, Hukum Tata Negara Indonesia, Jakarta: Sinar Bakti.

Sunggono, Bambang Sunggono, 2006, Metode Penelitian Hukum, Jakarta: PT. Raja Grafindo Persada.

Susilah, Ilah, 2010, Manajemen Bidan Praktik Mandiri, Yogyakarta: Dee Publish.

Soemitro, Ronny Hanitijo, 1985, Metodologi Penelitian Hukum Dan Yurimetri, Jakarta: Ghalia Indonesia.

Waluyo, Bambang, 2007, Penelitian Hukum dalam Praktek, Jakarta : PT. Raja Grafindo Persada.

Warassih, Esmi, Prananta Hukum Sebuah Telaah Sosiologis, 2011, Semarang: PT. Suryandaru Utama.

Wildan, Moh., Hidayat, A. Aziz Alimul, 2008, Dokumentasi Kebidanan, Jakarta : Salemba Medika.

William J. Chamblis \& Robert B. Seidman,1971, Law, Order, and Power. Mass : Addisin-Wesly

Zainuddin, 2008, Sosiologi Hukum, Jakarta : Sinar Grafika

http://www.edikusmiadi.com/2011/12/ha k-kewajiban-pasien-dan tenaga.html.

http://ejournal.uajy.ac.id/7870/3/2MIH012 83.pdf

https://www.academia.edu/13188669/pe nerapan standar dan dokumentasi asuhan kebidanan dalam mendukung jkn and AFTA 2015

http://wisehealth.itb.ac.id/files/kebidanan /ITB DES 2012, EDIT.pdf

http://www.jimly.com/makalah//Konsep_ Negara_Hukum_Indonesia.pdf

http://ibi.or.id/id/article_view/a20150115 001/bidan-delima.html

http://pknips.blogspot.co.id/2015/03/konsep -dan-arti-penting-perlindungandan-Penegakan-Hukum.html

Nusye Ki Jayanti, Penyelesaian Hukum Dalam Praktek Kedokteran, Pustaka Yustitia, Yogyakarta, 
1253 | Jurnal Idea Hukum

Vol. 5 No. 1 Maret 2019

Magister Hukum Fakultas Hukum Universitas Jenderal Soedirman

2009 ,

http://repository.unisba.ac.id/_tes 2016.pdf

Mahmūdah Khusnul Khotimah, 2016, http://digilib.unila.ac.id. BAB II.pdf

Soetanto Soepiadhy, 2012, Bekerjanya Hukum Dalam Masyarakat, http://www.surabayapagi.com,

Bekerjanya Hukum dalam

Masyarakat.html 